\title{
The Effects of Perspective-Taking on Perceptual Learning
}

\author{
Ehsan Hashemi Jabali ${ }^{\star}$ \\ Department of Foreign Languages, Islamic Azad University, Khorasgan Branch, Isfahan, Iran \\ *E-mail address: emigod_2020@yahoo.com
}

\begin{abstract}
Research in perceptual psychology and anthropology has demonstrated that experts will literally see objects and events in their domain differently than non-experts. Experts can make distinctions and notice subtleties that a novice does not perceive. Experts also have strategies for looking at data and artifacts in a domain; they know where to look so that they can answer the important questions. An expert perspective can be described as the ways of seeing and experiencing phenomena that are influenced by the specialized knowledge that an expert has. The present paper will survey the existing literature on perspective-taking and learning, with a short discussion at the end of some of the ways that existing technologies have been used to support the sharing of perspectives. Of particular interest in this paper is the potential to use new media technologies to convey the perspective of someone with specialized knowledge or insider information on an important event—a viewpoint that could be termed an "expert perspective."
\end{abstract}

Keyword: Perspective-taking; Perceptual Learning; Media Technology; Expert perspective; Psychology

\section{INTRODUCTION}

The perspectives that we adopt when interacting in the world play an integral role in the processes of thinking and learning. This notion is implicit in the way people speak informally about learning, such as when a tutor says to a struggling student "Maybe it would help if we approached this from a different perspective." In some areas of education, such as in history or literature, understanding perspectives is an explicit focus of the curriculum. And in everyday contexts, it has been suggested that perspective-taking is the primary mechanism with which humans are able to learn from others. Tomasello, Kruger, and Ratner (1993) assert that a learner attempts "to see the situation the way the other sees it-from inside the other's perspective as it were ... It is learning in which the learner is attempting to learn not from another but through another" (p. 496).

Attempts to foster learning through perspective-taking interventions in lab experiments have met with considerable success, but the logistical costs of implementing these activities in real educational contexts can be high, and in many cases the important perspectives are difficult or impossible to access. For example, valiant attempts have been made to convey to students in a classroom what it was like to fight under MacArthur in the Korean War or to be in the operation room of a particle accelerator. But without the ability to see these events 
through the eyes of the individuals who experienced them - to make discoveries the way that they discovered them - the instructional effectiveness of these attempts will likely be limited. Furthermore, the specific cognitive processes involved in making perspective-taking an effective instructional intervention are not fully understood, making it difficult to cultivate reliable pedagogies for a broad spectrum of educational topics. Therefore, if perspectivetaking is to have viable applications to learning, progress needs to be made on two fronts: 1) new and more potent methods for supporting perspective-taking in educational environments must be formulated and 2) rigorous and controlled study of the cognitive mechanisms that underlie various forms of perspective-taking must be conducted. This paper attempts to take modest steps forward on both of these fronts.

Making progress in these areas is aided by the emergence of new media technologies that can provide interactivity and compelling visual experience. Streaming digital video, interactive animations and simulations, touch-sensitive displays on tabletops and handheld devices, online virtual worlds, virtual reality and augmented reality are some of the platforms that have the potential to be used for enhancing perspective-taking. What makes perspectivetaking difficult as a purely mental activity is that it can be tremendously challenging to imagine and to simulate all the sensory components of another person's unique perspective (e.g., where they are looking and how they are interpreting what they see). Digital media technologies have the potential to relieve some of this burden on cognitive processing through high fidelity representations of these perceptual experiences. In other words, current technologies allow us to experience what it is like to be someone else-someone in a different location or with different experiences - with more realism than has ever before been possible.

Of particular interest in this paper is the potential to use new media technologies to convey the perspective of someone with specialized knowledge or insider information on an important event - a viewpoint that could be termed an "expert perspective." Research in perceptual psychology and anthropology has demonstrated that experts will literally see objects and events in their domain differently than non-experts (e.g., Goodwin, 1994). Experts can make distinctions and notice subtleties that a novice does not perceive. Experts also have strategies for looking at data and artifacts in a domain; they know where to look so that they can answer the important questions (Goodwin, 1995). An expert perspective can be described as the ways of seeing and experiencing phenomena that are influenced by the specialized knowledge that an expert has.

A digital technology that can convey an expert perspective in ways that can be taken up by novices would be a powerful step forward for education and for the creation of new designs for distributed intelligence (Pea, 1993). Such technologies would also provide a more controlled means of studying the psychological mechanisms of perspective-taking-by making small changes in the technology's design, researchers can look for big changes in learning behaviors. The present paper will survey the existing literature on perspective-taking and learning, with a short discussion at the end of some of the ways that existing technologies have been used to support the sharing of perspectives.

Assigning importance to the notion of perspective in human activity has been credited by some to the Greek philosopher Protagoras (Montgomery, 1994) who is best known for his statement of homo-mensura: "Of all things the measure is man, of the things that are, that they are, and of things that are not, that they are not" (DK80M). A perspective is how a person views some object or event as determined by the relationship they have with that object. This can be a physical relationship (e.g., the distance between the person and the object, the angle at which the object is viewed) or a psychological relationship (e.g., prior 
knowledge that the person has about the object, emotions that a person feels towards the object). The kind of relationship that a person has with an object-physical or psychological —will shape the ensuing interactions in ways that may make it easier or harder for learning to occur. For example, one would not expect someone to learn easily from an event that was in some way obstructed or something toward which the person had dismissive feelings.

In this paper I focus my examination on the process referred to as perspective-taking. Tomasello, Kruger, and Ratner (1993) define this process as "all the attempts of one person to understand or perceive a situation in the way that another person understands or perceives it" (p. 510). Most often perspective-taking denotes an indirect process utilizing empathy or imagination in an attempt to identify with the motives and experiences of another person. However, it is also possible to think about perspective-taking in a more literal sense, where someone has the opportunity to actually see and experience the world as another person experiences it. Achieving this second conceptualization of perspective-taking is becoming more feasible with the emergence of various technologies that can realistically convey a set of displaced experiences. This paper examines whether or not known affordances of the first, more indirect form of perspective-taking are shared with the more direct, technologymediated forms. Making this connection requires first understanding how perspective-taking in the traditional sense interacts with how people learn.

\section{DISCUSSION}

\subsection{How Perspective-Taking Can Influence Perceptual Learning}

Researchers have demonstrated benefits of having participants take on a new perspective for a wide range of activities including conflict management (Sessa, 1996), negotiation (Drolet, Larrick, \& Morris, 1998), strengthening interpersonal relationships (Arriaga \& Rusbult, 1998), volunteering and promoting altruistic behavior (Oswald, 1996), reducing stereotypes (Galinsky \& Gillian, 2004; Weyant, 2007), and increasing environmental awareness (Schultz, 2000; Sevillano, Aragones, \& Schultz, 2007). There is also the strong sense that perspective-taking can be beneficial for learning in the formal disciplines. For example, perspective-taking is an integral part of what is referred to as "historical thinking" and it is a practice that is often prescribed for students by researchers and practitioners in history education (e.g., Kohlmeier, 2005). In other areas, such as science and math, perspective-taking is often implicit in classroom pedagogies: "You need to approach this problem like a mathematician" or "What would be the important questions to ask if you were a biologist?"

Although there is a strong sentiment that learning is furthered by taking on new perspectives, it is not entirely clear why this is the case from a cognitive standpoint. There have been relatively few controlled studies where perspective is manipulated and learning outcomes are assessed.1 There are, however, a number of studies in psychology and education where perspective-taking is a salient component of the instructional intervention. This review of the literature begins with a summary of three ways that perspective-taking has been proposed to generate learning: organizing knowledge structures, leveraging social presence and social interaction, and through embodiment. Next, a small set of empirical studies that examined the effects of perspective-taking on various learning outcomes will be 
described. This chapter concludes with a survey of the various ways that new media technologies have been used to convey or simulate novel perspectives for learners.

\section{Organizing Structures of Knowledge}

Cognitive scientists have proposed a variety of representational structures, such as mental models and schemata, for how humans organize complex and relational knowledge about the world. The value of these structures is that they often exist as abstractions of phenomena, such that they can be applied generally to a range of different contexts and problems (de Vega, 1994). The process of perspective-taking may be a force behind the construction of these flexible structures. Ackerman (1996) states:

Perspective-taking provides a good example of how people drift in and out of their own viewpoint, and how this drifting leads to the building of a so-called "god's eye view" that transcends any particular vantage point, recreates hidden parts, and schematizes . . . in other words, imposes stabilities (p. 30).

This suggests that in the construction of new knowledge, perspective-taking can be the impetus for processes of data aggregation and statistical smoothing that result in stable and coherent representations.

Another possibility is that taking multiple perspectives puts an individual into a state of internal conflict, and that the effort and the deep processing required to reconcile the various perspectives leads to greater understanding and more powerful knowledge structures. Siegler (1995) demonstrated that directing someone to explain someone else's reasoning on a particular problem leads that individual to perform better on that problem themselves. It is suggested that an act of perspective-taking confronts the learner with deficiencies in their own reasoning, and motivates them to alter their existing knowledge to accommodate a potentially more effective strategy. This process of internal conflict resolution is very similar to the reconciliation that occurs within groups of individuals with different viewpoints who are working together to solve a problem. Doise \& Mungy

(1979) showed that dyads of children brought together to do a spatial transformation task benefited from this collaboration compared to individual performance, even if both of the children initially manifest an incorrect "centration" or a focus on a particular aspect of the problem. The conflict that arises through the act of perspective-taking appears to have a positive effect on knowledge construction, both for independent and collaborative learning activities.

\section{Social Presence and Social Interaction}

According to philosopher George Herbert Mead, perspective-taking, or taking the role of the other, is a critical component of developing one's understanding of the self in relation to the social world (Mead, 1934). Perspective-taking can be thought of as a fundamentally social process because even in isolation it necessitates empathy and the consideration of another's mental state. This notion is supported by several recent neuroscience studies that show activation in areas in the prefrontal cortex linked to social cognition during experimentally controlled acts of changing perspectives (D'Argembeau et al., 2007; Decety \& Sommerville, 2003; Ruby \& Decety, 2004). Other researchers have described how social games such as hide-and-seek and peek-a-boo help develop the perspective-taking capacity in children (Gillespie, 2006). 
If perspective-taking adds a social component to a non-social activity, the learning potential of that activity may be increased. Some recent experiments have compared social versus non-social versions of the same activity and found significant learning gains for participants in the social condition. Kuhl, Tsao, and Liu (2003), for example, showed that exposing babies to a foreign language improved their capacity for phonetic discrimination, but only if this exposure occurred in-person through an experimenter present at the session, and not when the same language stream was presented through a video recording presented to the child on DVD. Likewise, Okita, Bailenson, and

Schwartz (2007) conducted a study in virtual reality and found that people learned more when they believed that the virtual character they were interacting with was controlled by a real person compared to a computer program.

Experimental studies showing the effects of social presence on learning is complemented by qualitative and ethnographic accounts of learning in authentic social environments. Researchers studying a wide range of cultural activities, from the practices of tailors in Western Africa to American classrooms, have argued that the social structures that comprise these activities are inseparable from the learning that occurs in these contexts (Brown, Collins, \& Duguid, 1988; Lave \& Wenger, 1991; Scardamalia \& Bereiter, 1994). In settings where social interaction is not a natural component, such as in traditional distance education, learning is furthered when social interaction can be injected into the activity (Kanuka \& Anderson, 1998, Kearsley \& Shneiderman, 1999).

This can be enabled with collaborative projects or simply making text chatting available for remote students to engage socially. Finally, a meta-analysis by Lou, Abrami, and d'Apollonia (2001) showed that on average, children who are doing computer-based activities in schools tended to learn more when this work was done in the context of small groups as opposed to working independently.

Social interactions naturally require people to take the perspectives of the people they are interacting with in order to understand what others are seeking to do and to forge a successful collaboration. Having more opportunities for perspective-taking would seem to be advantageous for learning. A provocative study from research in artificial intelligence highlights this point. Breazeal, Berlin, Brooks, Gray, and Thomaz (2006) describe how they were able to program a robot that learned how to do a simple motor task (turning on a set of buttons) by simulating the visual perspective of the human who demonstrated the task. The robot was able to learn successfully, even if the human teacher made mistakes, because it could use its model of the human actor's understanding of the events to collect more data and resolve ambiguities.

\section{Embodiment}

Embodiment refers to the notion that human cognition in borne out of our basic physiology - that the form and functions of our bodies steer and constrain our processes of thinking (e.g., Lakoff \& Johnson, 1999). Because the perspectives that we possess are largely influenced by the positioning and the action taken by our bodies, the embodiment literature puts a great deal of emphasis on perspective as a factor in how we think about the world. If we extend this line of reasoning to perspective-taking, then it follows that mentally simulating the body-based experiences of other individuals may translate into new kinds of thinking and provide a basis for constructing new knowledge.

Much of the evidence for perspective-taking as a means for embodied learning comes from cognitive neuroscience. Brain research in the last decade has shown a compelling 
relationship between the observation/simulation of another person's activity and the activation of brain areas that have been traditionally associated with instigating and monitoring one's own activity, such as the motor cortex. Rizzolatti and Arbib (1998) showed that a particular segment of the macaque monkey's motor cortex is activated both when the monkey grasps an object and when it observes a human performing a similar action. The authors proposed the existence of "mirror neurons" as a potential means for the brain to relate the actions of others to performing these actions with one's own body.

In theorizing about the function of mirror neurons in humans, Wilson and Knoblich

(2005) took it a step farther and suggested that these areas of the brain actually function as "motor emulators" that simulate someone's physical movements in real time, allowing them to predict future movement and fill in perceptual gaps in their observations. This covert form of perspective-taking may be part of the mechanism that enables us to respond so fluidly and efficiently to the actions of others in highly complex activities such as dance or hand-to-hand combat.

Beyond basic observation and imitation of body movement, there is also evidence that suggests that our brain physiology equips us to engage in empathy and the kinds of perspective-taking that are necessary to interpret language and acquire new knowledge.

Rohrer (2005) cites studies of patients with body-part language deficiencies to argue that the motor cortices are integral to the semantic comprehension of body and actioncentered descriptions in language. Furthermore, a study by Kosslyn, Thompson, Wraga, and Alpert (2001) demonstrates that the activation of these body-centered forms of knowledge organization can be triggered by an experimenter-induced act of perspective-taking.

In this study participants either watched an object being rotated by an electric motor or they were asked to physically rotate the objects themselves. All subjects were then put in the scanner where they performed a mental rotation of the same object. Subjects who had rotated the objects manually experienced activation in the motor cortex during the mental rotation task, whereas subjects who watched the object rotating did not have activation in this area.

As the Kosslyn et al. (2001) study suggests, taking an action-based perspective has the greatest potential for improving performance and generating learning, and this premise is further supported in behavioral studies. For example, Lozano, Hard, and Tversky (2006) showed that taking an actor perspective as opposed to an observer perspective when viewing an assembly task resulted in higher proficiency when the participant was asked to perform the task themselves. There is also evidence that suggests that when learning is the objective, people will instinctively gravitate toward the adoption of an action perspective. In studies of participants' comprehension of a narrative, for example, the participants showed faster recall for elements of the setting described in the narrative that were located "closer" to the protagonist (Bower \& Morrow, 1990; Morrow, Bower, \& Greenspan, 1989). This result suggests that the participants had constructed a spatial mental model of the narrative setting commensurate with the protagonist's perspective, and consequently their ability to reason spatially was constrained by the protagonist's physical location. Another indication that people will attempt to adopt action perspectives is the tendency to supplement reasoning and language tasks with body movement. People who are asked to give directions to a local landmark will often accompany their verbal directions with a twisting of their torso and other gestures that are aligned with the listener's perspective (Kita, 2003).

A final source of evidence for learning as an embodied process comes from anthropological studies of experts. With more experience, a person's activity in a domain will typically show greater stability and organization. Observations of experienced participants engaging in these activities indicate, however, that expert performance is not merely a 
product of having more explicit knowledge of the activity. Rather, proficiency in a domain is often exhibited through the ways a person structures visual and other perceptual information relevant to the domain in the course of their activity. This perceptual property of expert performance has been referred to as both professional vision (Goodwin, 1994) and disciplined perception (Stevens \& Hall, 1998; Stevens, 1999). As an example, Goodwin (1994) describes the sophisticated ways in which an archeologist marks and discriminates dirt patterns at an excavation site-patterns that are literally undetectable to a novice in this domain. The training process for novices in archeology typically involves opportunities for apprenticeship where an expert attempts to share their skillful perspective through processes such as highlighting or presenting informative contrasts. In this view of human activity and learning, knowledge is not simple influenced by our processes of perception; it is contained within these processes.

\section{CONCLUSION}

A conspicuous characteristic of the prior research that has been conducted on perspective-taking and its various effects on people's capacity to learn is how scattered and often discordant it is. Perspectives can be influenced by a number of different factors (prior experience, beliefs, physical positioning, etc.) and consequently there are at least as many ways that a person can attempt an act of perspective-taking. The literature review revealed a number of demonstrated learning benefits of perspective-taking, but there has been no clear agreement on what are the specific cognitive mechanisms that produce these benefits. Studies of perspective-taking and learning come from an array of different research disciplines such as sociology, neuroscience, and computer science, and frequently the terminology used to discuss perspective-taking (e.g., point of view, empathy, etc.) are not shared by all disciplines. While there is certainly more progress that must be made, the research synthesis in this paper identified some common themes in the explanations of the learning benefits of perspective-taking that could provide the basis for future studies and interdisciplinary collaborations. These themes are: the role of perspective-taking in organizing structures of knowledge, social interaction, and embodiment. Each of these themes are a potential framework for looking at how perspective-taking supports processes of learning and can provide a common lens that can be shared across diverse researchers. The hope is that this reformulation can serve as a "re-boot" of the perspective-taking literature that over the last few decades has lost interest and influence.

\section{References}

[1] Ackermann, E. (1996). Perspective-taking and object construction. In Y. Kafai \& M. Resnick (Eds.), Constuctionism in practice: Designing, thinking, and learning in a digital world (pp. 25-37). Mahwah, New Jersey: Lawrence Erlbaum Associates.

[2] Anderson, R. C, Pichert, J. W., \& Shirey, L. L. (1983). Effects of the reader's schema at different points in time. Journal of Educational Psychology, 75(2), 271-279.

[3] Arriaga, X. B., \& Rusbult, C. E. (1998). Standing in my partner's shoes: Parmer perspective taking and reactions to accommodative dilemmas. Personality \& Social Psychology Bulletin, 24(9), 927-948. 
[4] Bower, G. H., \& Morrow, D. G. (1990). Mental models in narrative comprehension. Science, 47, 44-48.

[5] Breazeal, C, Berlin, M., Brooks, A., Gray, J., \& Thomaz, A. L. (2006). Using perspective taking to learn from ambiguous demonstrations. Robotics and Autonomous Systems, 54, 385-393.

[6] Brown, J. S., Collins, A., \& Duguid, P. (1989). Situated cognition and the culture of learning. Education Researcher, 18(1), 32-42.

[7] D'Argembeau A., Ruby P., Collette F., Degueldre C, Balteau E., Luxen A., et al. (2007). Distinct regions of the medial prefrontal cortex are associated with self-referential processing and perspective taking. Journal of Cognitive Neuroscience, 19(6), 935- 955.

[8] Decety, J., \& Sommerville, J. A. (2003). Shared representations between self and others: A social cognitive neuroscience view. Trends in Cognitive Sciences, 7, 527-533.

[9] de Vega, M. (1994). Characters and their perspectives in narratives describing spatial environments. Psychological Research, 56,116-126.

[10]Doise, W., \& Mungy, G. (1979). Individual and collective conflicts of centrations in cognitive development. European Journal of Psychology, 9, 105-108.

[11]Falk, D. R., \& Johnson, D. W. (1977). The effects of perspective-taking and egocentrism on problem solving in heterogeneous and homogeneous groups. The Journal of Social Psychology, 102, 63-72.

[12] Galinsky, A. D., \& Gillian, K. (2004). The effects of perspective-taking on prejudice: The moderating role of self-evaluation. Personality and Social Psychology Bulletin, 30(5), 594-604.

[13] Gillespie, A. (2006). Games and development of perspective taking. Human Development, 49, 87-92.

[14] Goodwin, C. (1994). Professional vision. American Anthropologist. 96,606-633.

[15] Goodwin, C. (1995). Seeing in depth. Social Studies of Science, 25, 237-274.

[16] Kanuka, H., \& Anderson, T. (1998). Online social interchange, discord, and knowledge construction. Journal of Distance Education, 13(1), 51-1 A.

[17] Kearsley, G., \& Shneiderman, B. (1999). Engagement theory: A framework for technology-based teaching and learning. Retrieved November, 19,2007, from http://home.sprynet.com/ gkearsley/engage.htm

[18] Kita, S. (2003). Interplay of gaze, hand, torso orientation and language in pointing. In S. Kita (Ed.), Pointing: Where language, cognition and culture meet (pp. 307-328). Mahwah, NJ: Lawrence Earlbaum Associates.

[19] Kohlmeier, J. (2005). The impact of having 9th graders "do history." The History Teacher, 38(4), 499-525.

[20] Kosslyn, S. M., Thompson, W. L., Wraga, M., \& Alpert, N. M. (2001). Imagining rotation by endogenous versus exogenous forces: Distinct neural mechanisms. NeuroReport, 12,2519-2525. 
[21] Kuhl, P. K., Tsao, F. M., \& Liu, H. M. (2003). Foreign-language experience in infancy: Effects of short-term exposure and social interaction on phonetic learning. Proceedings of the National Academy of Sciences, USA. 100, 9096-9101.

[22] Lakoff, G., \& Johnson, M. (1999). Philosophy in the flesh: Embodied mind and its challenge to western thought. New York: Basic Books.

[23] Lave, J., \& Wengef, E. (1991). Situated learning: Legitimate peripheral participation. Cambridge: Cambridge University Press.

[24]Lou, Y., Abrami, P. C, \& d'Apollonia, S. (2001). Small group and individual learning with technology: A meta-analysis. Review of Educational Research, 77(3), 449- 521.

[25]Lozano, S. C, Hard, B. M., \& Tversky, B. (2006). Perspective taking promotes action understanding and learning. Journal of Experimental Psychology: Human Perception and Performance, 32(6), 1405-1421.

[26] Mead, G. H. (1934). Mind, self, \& society from the standpoint of a social behaviorist (C. W. Morris, Ed.). Chicago, IL: University of Chicago Press.

[27] Montgomery, H. (1994). Towards a perspective theory of decision-making and judgment. Acta Psychologica, 87, 155-178.

[28] Morrow, D. G., Bower, G. H., \& Greenspan, S. (1989). Updating situation models during narrative comprehension. Journal of Memory and Language, 28, 292-312.

[29] Okita, S. Y., Bailenson, J., \& Schwartz, D. L. (2007). The mere belief of social interaction improves learning. Proceedings of the Twenty-ninth Meeting of the Cognitive Science Society. Nashville, TN.

[30] Oswald, P. A. (1996). The effects of cognitive and affective perspective taking on empathetic concern and altruistic helping. The Journal of Social Psychology, 136(5), 613-623.

[31] Pea., R. (1993). Practices of distributed intelligence and designs for education. In G. Salomon (Ed.), Distributed cognitions (pp. 47-87). Cambridge, UK: Cambridge University Press.

[32]Pea, R., Mills, M., Rosen, J., Dauber, K., Effelsberg, W., \& Hoffert. E. (2004). The DIVER project: Interactive digital video repurposing. IEEE Multimedia, 7/(1), 54-61.

[33] Rizzolatti, G., \& Arbib, M. A. (1998). Language within our grasp. Trends in Neurosciences, 21(5), 188-194.

[34] Rohrer, T. (2005). Image schemata in the brain. In B. Hampe \& J. Grady (Eds.), From perception to meaning: Image schemas in cognitive linguistics (pp. 165-196). Berlin: Mouton de Gruyter.

[35] Ruby, P., \& Decety, J. (2004). How would you feel versus how do you think she would feel? A neuroimaging study of perspective-taking with social emotions. Journal of Cognitive Neuroscience, 16(6), 988-999.

[36] Scardamalia, M., \& Bereiter, C. (1994). Computer support for knowledge-building communities. The Journal of the Learning Sciences, 3(3), 265-283.

[37] Schultz, P. W. (2000). Empathizing with nature: The effects of perspective taking on concern for environmental issues. Journal of Social Issues, 56(3), 391-406. 
[38] Sessa, V. I. (1996). Using perspective taking to manage conflict and affect in teams. The Journal of Applied Behavioral Science, 32(1), 101-115.

[39] Sevillano, V., Aragones, J. I., \& Schultz, P. W. (2007). Perspective taking, environmental concern, and the moderating role of dispositional empathy. Environment and Behavior, 39(5), 685-705.

[40] Siegler, R. S. (1995). How does change occur: A microgenetic study of number conservation. Cognitive Psychology, 28, 225-273.

[41] Stevens, R. R. (1999). Disciplined perception: Comparing the development of embodied mathematical practices in school and at work. Unpublished Dissertation, University of California at Berkeley, Berkeley, CA.

[42] Stevens, R. R., \& Hall, R. (1998). Disciplined perception: Learning to see in technoscience. In M. Lampert \& M. L. Blunk (Eds.), Talking mathematics in school: Studies of teaching and learning (pp. 107-149). Cambridge, UK: Cambridge University Press.

[43] Tomasello, M., Kruger, A. C, \& Ratner, H. H. (1993). Cultural learning. Behavioral and Brain Sciences, 16,495-552.

[44] Weyant, J. M. (2007). Perspective taking as a means of reducing negative stereotyping of individuals who speak English as a second language. Journal of Applied Social Psychology, 37(4), 703-716. 